\title{
La Reclusión de la Comunidad Transexual en Centros Penitenciarios para hombres una decisión al Arbitrio del Juez Penal
}

\author{
The Imprisonment of the transsexual community in prisons for me: A Decision at the discretion \\ of the criminal judge
}

Denitza. López-Téllez ${ }^{a}$

\begin{abstract}
:
The structural content of this paper first includes a conceptual framework where terms such as gender, gender identity, equality and discrimination are addressed, then a review in both international and national instruments that are address an issue of equality and non- discrimination as well as some documents, such as the origins of Yogyakarta in relation to the deprivation of people, who are deprived frim their liberty, likewise, article 18 of the Political Constitution of Mexico is reviewed, as well as reports on the subject on transsexual people who have been deprived prom their freedom. Their freedom, according the construed interpretation, transgender people who have sentenced to serve a sentence within a social rehabilitation center or have been detained in pre-trial detention must be assigned the centers corresponding to their gender, as a result to a full development of the person and be a person who has been judged with a gender perspective.

The rights of the transsexual community are addressed when being sentenced to serve a prison term in detention centers for men, as a vulnerable group, the rights of the Transsexual Community are covered when they are to serve a prison sentence in a center where they have their sexual orientation. This analizes the applicability and openability of human rights in the LBTTI Community in prison. Lastly, the need to create a protocol, in which the transsexual community in the stage of serving a sentence and security measures is adressed,

In our national, international and in some federal entities there are several legal instruments that are defusing a state that does not comply with democratic principles, so it's necessary to adapt the infrastructure, which leaves the binary nature of the genders, so that we live in an inclusive country.
\end{abstract}

Keywords:

Gay, discrimination, Equality, sexual orientation, transsexual

\section{Resumen:}

El contenido estructural del presente ensayo abarca en primer término un marco conceptual donde se abordan los términos de sexo, género, identidad de género, igualdad y discriminación, posteriormente se hace una revisión en instrumentos internacionales y nacionales que abordan lo referente a la igualdad y no discriminación así como algunos documentos como los principios de Yogyakarta en relación a la privación de personas privadas de su libertad, de igual manera se revisa el art 18 de la Constitución Política de los Estados Unidos mexicanos así como informes en materia de personas transexuales privadas de su libertad de acuerdo a una interpretación conforme las personas transgéneros que han sido sentenciados a cumplir una pena dentro de un Centro de Reinserción Social o han sido detenidos en prisión preventiva deben de asignarse al centro de que corresponda al género que se han conducido, como resultado a una desarrollo pleno de la persona y ser persona que ha sido juzgada con perspectiva de género.

Se abordan los derechos de la comunidad transexual al ser sentenciados a cumplir una pena de prisión en Centros de Internamiento para hombres, como grupo vulnerable se abarcan los derechos de la Comunidad Transexual cuando cumplen una pena de prisión en un centro distinto a su orientación sexual se analiza la aplicabilidad y operatividad de los derechos humanos en la comunidad LBTTI en prisión.

Por último se aborda la necesidad de crear un Protocolo para la comunidad transexual en la etapa del cumplimiento de penas y medidas de seguridad.

En nuestra normativa Nacional, Internacional y en algunas entidades federativas existen diversos instrumentos jurídicos que no se aplican es un problema de estructura jurídica, de difusión de un Estado que no cumple principios democráticos, por lo que es necesario que se adecue la infraestructura, que deje el carácter binario de sexos que vivamos en un país incluyente. 


\section{Palabras Clave:}

Gay, discriminación, Igualdad, orientación sexual, transexual et

\section{Introducción}

Si a todas las personas de un Estado de Derecho tratáramos de manera igual y equidad, respetáramos sus decisiones en aras de su ejercicio de libertad, se habría evitado la creación de diversas leyes de protección a minorías y grupos vulnerables, no se trata de legislar cada situación, ni crear nuevas leyes para la comunidad LGBBTTI, se trata de aplicar de manera igual el derecho a la no discriminación y el principio universal de igualdad. Si a eso se adhiere que existen personas LGBTTTI que han cometido un delito y se encuentran penalmente responsables ¿A qué prisión se les debe de enviar?, ¿Compurgaran su sentencia con hombres o con mujeres? ¿Con que derechos cuentan en la etapa de ejecución de penas?

Sin bien la comunidad LGBT son objeto de violaciones a sus Derechos Humanos en una realidad social, lo son más cuando cumplen una pena en prisión, en diversas entidades de nuestro país, compurgar una pena en un centro de internamiento se enfoca a determinar si eres hombre o mujer, por lo que esta minoría, es sometida a una decisión del juez sin un control de convencionalidad, que no atiende su orientación sexual, sino al sexo biológico con el que nacieron, nos enfrentamos a una vulneración de sus derechos humanos, previstos en la Constitución Política de los Estados Unidos Mexicanos (CPEUM) y los Tratados internacionales. Este documento tendrá como conclusión voltear a ver a la comunidad LGBTI, sus características, y los abusos de los cuales han sido víctimas en los Centros de Internamiento.

\section{Marco Conceptual}

La terminología que se hace referencia en este apartado se basa en el Protocolo de Actuación para quienes imparten Justicia en casos en que se involucren la orientación sexual e identidad de género, expedido la Suprema Corte de Justicia de la Nación (SCJN, el Protocolo de Actuación para quienes imparten Justicia en casos en que se involucren la orientación sexual e identidad de género, 2014)

Sexo:

Cuando se habla de sexo se hace referencia a cuerpos sexuados de las personas esto es de acuerdo a las características biológicas, hembra o macho.

Género:
Se refiere al resto de los atributos que permiten distinguir a un hombre una mujer e incluso un intersex, es decir se refiere a las características que social, histórica y culturalmente se refieren a hombres y mujeres al considerar características masculinas o femeninas, como características que se le suelen atribuir a cada sexo como la delicadeza, la fuerza, los roles, deportes, gustos así las actitudes que utilizan los hombres o mujeres, como la forma de vestir, caminar, hablar o comportarse.

De ahí que algunas personas se consideran "mujeres trans" cuando su sexo biológico es de hombre y otras se consideran "hombres trans" cuando su sexo biológico es de mujer, no obstante algunas personas se consideran hombres o mujeres, derivado de lo anterior así deben de ser respetados cultural, social y legalmente, de ello resulta necesario respetar la libertad de decisión de la persona. Para referirse a las personas trans también se han usado otros términos como travestis, transgénero y transexual.

La Identidad de género:

Es la manera en como una persona se asume así misma, es decir opta por una identidad de género masculina o femenina que no concuerda con el sexo al nacer

Expresión de Género:

La CIDH es la "manifestación externa de los rasgos culturales que permiten identificar a una persona como masculina o femenina conforme a los patrones propios de cada género por una determinada sociedad en un momento histórico.

Igualdad:

Desde un enfoque de derechos humanos, exige el reconocimiento de las diferencias que hay entre las personas, en razón de que es la valoración de tales diferencias en unión con el contexto material y cultural lo que coloca a las personas en distinta situaciones normativas y fácticas (en desigualdad) y en posibilidad o imposibilidad de ejercer un derecho.

Existe la igualdad formal: Es decir todos los hombres y mujeres son iguales ante la ley (art 1 CPEUM), la igualdad material: el sexo, el género, las preferencias sexuales, orientaciones sexuales, no obstante que está reconocida la igualdad formal, no es posible que las personas gocen de esos mismos derechos. (Art 4.1 de la Convención sobre la eliminación de todas las formas de discriminación contra la mujer) y la igualdad Estructural: colocan a las personas sin posibilidad de opción en grupos históricamente marginados y sometidos (inmigrantes, la comunidad LGBTI, indígenas, existen prejuicios, estereotipos que se basan en la premisa de inferioridad). 
(Art 8 de la Convención Interamericana para Prevenir, Sancionar y Erradicar la violencia contra la mujer) (SCJN, Protocolo para juzgar con perspectiva de Género. Haciendo relidad el derecho a la igualdad., 2013).

Discriminación:

Toda distinción, exclusión o restricción basada en género, sexo, preferencias sexuales, edad, discapacidad, condición social, religión, raza, color, idioma, o cualquier otra condición social que tenga por objeto o por resultado impedir, anular o menoscabar el reconocimiento, goce o ejercicio en condiciones de igualdad de los derechos humanos y libertades fundamentales en cualquier esfera. (Ley General para la igualdad entre mujeres y hombres, 2016),

Sin embargo, no todo trato diferenciado es discriminatorio si se circunscribe en un marco de justicia, tal como lo establece la siguiente tesis jurisprudencial.

GARANTÍA DE NO DISCRIMINACIÓN. SU PROTECCIÓN CONSTITUCIONAL. De los artículos 10., párrafo tercero, y 40., párrafo primero, de la Constitución Política de los Estados Unidos Mexicanos, se advierte que la no discriminación es una verdadera garantía individual, consistente en el derecho subjetivo público del gobernado de ser tratado en la misma forma que todos los demás y el correlativo deber jurídico de la autoridad de garantizar un trato idéntico a todas las personas ubicadas en las mismas circunstancias. Ahora bien, conforme a tales preceptos, en la Nación Mexicana está prohibido todo tipo de discriminación que atente contra la dignidad humana, anule o menoscabe los derechos y libertades del varón y la mujer, porque ambos deben ser protegidos por la ley sin distinción alguna, independientemente de sus preferencias $\mathrm{y}$, por ello, deben gozar de los mismos derechos y de la igualdad de oportunidades para ejercer las libertades fundamentales en las esferas política, económica, social, cultural, civil o en cualquier otra.

Amparo directo en revisión 881/2007. Ángel Flores Merino. 4 de julio de 2007. Cinco votos. Ponente: Sergio Salvador Aguirre Anguiano. Secretario: Alberto Miguel Ruiz Matía

No olvidemos un antecedente discriminatorio de la existencia de la crujía en el palacio de Lecumberri la crujía "j"

En Lecumberri se encontraba la celda o crujía j, donde se internaban a los presos que cometían el delito de homosexualidad, a partir de entonces se les llama de forma despectiva a los homosexuales "jotos" (Aldeberán, 2012).

\section{Normatividad}

Diversos organismos internacionales y locales han establecido la prohibición de la discriminación por motivos de orientación sexual e identidad de género, si a esto se le suma la privación de la libertad es necesario que el Poder Judicial enfrente este reto y el juez atendiendo a los principios de convencionalidad y control constitucional juzgando con perspectiva de género revise estos instrumentos en aras a la protección de los Derechos Humanos de las personas LGBTTI que son privas de la libertad.

\section{Instrumentos Internacionales}

En materia de Derechos Humanos, podemos aplicar los siguientes: Convención Interamericana para Prevenir y Sancionar la Tortura; Convención Interamericana sobre Desaparición Forzada de Personas; Convención Interamericana para Prevenir, Sancionar y Erradicar la Violencia contra la Mujer; Convención Interamericana para la Eliminación de todas las formas de Discriminación contra las Personas con Discapacidad; Declaración Americana de Derechos y Deberes del Hombre; Pacto Internacional de Derechos Civiles y Políticos; Pacto Internacional de Derechos Económicos, Sociales y Culturales; Convención contra la Tortura y otros Tratos o Penas Crueles, Inhumanos o Degradantes, y su Protocolo Opcional; Convención sobre los Derechos del Niño; Convención sobre la Eliminación de todas las formas de Discriminación contra la Mujer (CEDAW); Convención Internacional para la Protección de todas las Personas contra las Desapariciones Forzadas; Convención Internacional sobre la Protección de los Derechos de todos los Trabajadores Migratorios y de sus Familiares; Convención sobre la Eliminación de todas las formas de Discriminación Racial; Convención numero 169 sobre Pueblos Indígenas y Tribales en países independientes; Convenios de Ginebra de 12 de agosto de 1949, y sus Protocolos Adicionales de 1977; Declaración Universal de Derechos Humanos; Declaración sobre los Principios Fundamentales de Justicia para las Víctimas de Delitos y del Abuso de Poder; Principios Básicos para el Tratamiento de los Reclusos; Conjunto de Principios para la Protección de todas las Personas sometidas a cualquier forma de Detención o Prisión; Principios para la Protección de los Enfermos Mentales y el mejoramiento de la atención de la Salud Mental; Reglas Mínimas para el Tratamiento de los Reclusos; Reglas Mínimas de las Naciones Unidas para la Administración de la Justicia de Menores (Reglas de Beijing); Reglas de las Naciones Unidas para la Protección de los Menores Privados de Libertad; Reglas Mínimas de las Naciones Unidas sobre las Medidas no Privativas de Libertad (Reglas de Tokio); $y$ en otros instrumentos internacionales sobre derechos 
humanos aplicables en las Américas así como los principios de Yogyakarta (PDY), mismos que representan un avance normativo para las personas lesbianas, gays, bisexuales, transgeneros intersexuales (LGBTI), ya que es la primera vez que se realiza un documento por 25 países y expertos en materia de Derechos Humanos con estas características destinados a la protección de los Derechos Humanos de la comunidad LBTI, mismas que constituyen una valiosa fuerza interpretativa de la ley para impartir justicia, legislar con igualdad en un Estado Social y Democrático de Derecho, actualmente solo son vistos como un documento doctrinal. (Pulgarin, 2011)

Que establece en el principio 9 que toda El Derecho de toda persona privada de su libertad a ser tratada humanamente:

Toda persona privada de su libertad será tratada humanamente y con el respeto a la dignidad inherente al ser humano. La orientación sexual y la identidad de género son fundamentales para la dignidad de toda persona.

C.-Garantizarán que, en la medida que sea posible, todas las personas privadas de su libertad Participen en las decisiones relativas al lugar de detención apropiado de acuerdo a su orientación sexual e identidad de género;

D. Establecerán medidas de protección para todas las personas privadas de su libertad que resulten vulnerables a la violencia o los abusos por causa de su orientación sexual, identidad de género o expresión de género y asegurarán que dichas medidas no impliquen más restricciones a sus derechos de las que experimenta la población general de la prisión, en la medida en que esto pueda llevarse razonablemente a la práctica;

E. Asegurarán que las visitas conyugales, donde estén permitidas, sean otorgadas en igualdad de condiciones para todas las personas presas y detenidas, con independencia del sexo de su pareja;

F. Estipularán el monitoreo independiente de los establecimientos de detención por parte del Estado, como también de organizaciones no gubernamentales, incluyendo aquellas que trabajan en los ámbitos de la orientación sexual y la identidad de género;

G. Emprenderán programas de capacitación y sensibilización dirigidos al personal penitenciario y a todos los otros funcionarios y funcionarias de los sectores público y privado involucrados en los establecimientos de detención sobre las normas internacionales de derechos humanos y los principios de igualdad y no discriminación, incluidos los referidos a la orientación sexual y la identidad de género.

Si bien los principios de Yogyakarta no son vinculantes lo cierto es que un juez al sentenciar a una persona de la comunidad LGBTI y por lo que hace a este tema especialmente aquel hombre o mujer transexual tiene la estricta responsabilidad en caso de detención judicial, preguntarle al indiciado, procesado que se encuentre en prisión preventiva, sentenciado, el lugar donde quiere compurgar su condena en un establecimiento destinado para hombres o mujeres, pues dicha decisión no puede quedar a su arbitrio, pues de acuerdo a un control de convencionalidad "ex officio" está obligado a revisar la legislación y si ésta vulnera los derechos humanos el no deberá aplicarla. De la misma manera tiene que juzgar con perspectiva de género.

En el año 2011 se adoptó la resolución 17/19 relativa a la "orientación sexual" e "identidad de género" La Organización de las Naciones Unidas ONU mediante en el Consejo de Derechos Humanos se han establecido ciertos criterios respecto de cómo los Estados deben incorporar medidas legislativas a fin de proteger a las personas de la comunidad LGBTTI, que pertenecen al derecho penal objetivo a nivel nacional e internacional con fundamento en la Declaración Universal de los Derechos Humanos y en los tratados internacionales de Derechos Humanos, dentro de estos derechos podemos encontrar cinco recomendaciones como obligación de los Estados de ofrecer mecanismos especializados para la no repetición de todas las formas de discriminación (Naciones Unidas, 2012) :

Proteger.- A las personas con violencia homofóbica y transfobica.

Prevenir La Tortura y los Tratos crueles e inhumanos.

Derogar las leyes que tipifiquen la homosexualidad

Prohibir la discriminación de la orientación sexual e identidad de género.

Salvaguardar la libertad de expresión asociación y reunión pacifica de las personas LGBTTI.

De estas recomendaciones podemos advertir nuevamente que se tiene que prohibir la discriminación por orientación sexual e identidad de género.

Principios y buenas prácticas sobre la protección de las personas privadas de libertad en las Américas.

Este documento básico en materia de Derechos Humanos en el Sistema Interamericano reconoce el derecho fundamental que tienen todas las personas privadas de la libertad a ser tratadas humanamente que se respete y garantice la dignidad, su vida, integridad física, psicológica y moral. En el segundo principio se establece la Igualdad y no discriminación que a la letra establece:

"Bajo ninguna circunstancia se discriminará a las personas privadas de su libertad por motivos de su raza, origen étnico, nacionalidad, color, sexo, edad, idioma, religión opiniones políticas o de otra índole, origen nacional o social, posición económica, nacimiento, discapacidad física, mental o sensorial, género, 
orientación sexual, o cualquiera otra condición social. En consecuencia, se prohibirá cualquier distinción, exclusión o restricción que tenga por objeto o por resultado, menoscabar o anular el reconocimiento, goce o ejercicio de los derechos internacionalmente reconocidos a las personas privadas de la libertad" (CIDH, 2008)

La Organización de las Naciones Unidas (Comunicado de Prensa 53/2015) La Comisión Interamericana de Derechos Humanos (CIDH) En el año 2015 CIDH expresa preocupación por violencia y discriminación contra personas LGBT privadas de libertad. La comisión hace un llamado de atención a los Estados parte de la Organización de los Estados Unidos Mexicanos para que adopten medidas a urgentes y eficaces para que la comunidad LGBT o personas percibidas como tales en los establecimientos de detención incluyendo cárceles, y los centros de detención de migrantes.

Según la CIDH Los tipos de violencia que más surgen las personas LGBT son: Violencia Sexual (agresiones sexuales), Actos y Abuso de discriminación, Se aplica aislamiento solitario como medida habitual para "proteger" ya que como lo establece el aislamiento puede producir daños mentales y físicos. Por otro lado dicho comunicado 053 de 2015 establece que la violencia sexual contra las mujeres trans se intensifica cuando se les asigna en instalaciones para hombres, sin tener en cuenta la persona o el caso. Las decisiones sobre donde alojar a las personas trans debe efectuarse en cada caso, con respeto a su dignidad personal y en la medida de lo posible consultando previamente a la persona. (OEA, 2015)

\section{Instrumentos Legales Nacionales}

De una interpretación conjunta aplicando el principio de convencionalidad el juez penal al dictar una sentencia acorde con los tratados internacionales y nuestra carta magna se debe juzgar con perspectiva de género.

Con fundamento en el art 1 de la Constitución Política De Los Estados Unidos Mexicanos en Adelante la CPEUM, que a la letra establece:

Título Primero De los Derechos Humanos y sus Garantías "Artículo 10. En los Estados Unidos Mexicanos todas las personas gozarán de los derechos humanos reconocidos en esta Constitución y en los tratados internacionales de los que el Estado Mexicano sea parte, así como de las garantías para su protección, cuyo ejercicio no podrá restringirse ni suspenderse, salvo en los casos y bajo las condiciones que esta Constitución establece. Las normas relativas a los derechos humanos se interpretarán de conformidad con esta Constitución y con los tratados internacionales de la materia favoreciendo en todo tiempo a las personas la protección más amplia.
Todas las autoridades, en el ámbito de sus competencias, tienen la obligación de promover, respetar, proteger y garantizar los derechos humanos de conformidad con los principios de universalidad, interdependencia, indivisibilidad y progresividad. En consecuencia, el Estado deberá prevenir, investigar, sancionar y reparar las violaciones a los derechos humanos, en los términos que establezca la ley.

Está prohibida la esclavitud en los Estados Unidos Mexicanos. Los esclavos del extranjero que entren al territorio nacional alcanzarán, por este solo hecho, su libertad y la protección de las leyes.

Queda prohibida toda discriminación motivada por origen étnico o nacional, el género, la edad, las discapacidades, la condición social, las condiciones de salud, la religión, las opiniones, las preferencias sexuales, el estado civil o cualquier otra que atente contra la dignidad humana y tenga por objeto anular o menoscabar los derechos y libertades de las personas"

A partir de la reforma del 10 de junio de 2011 el Estado mexicano se compromete a incorporar en sus resoluciones y operatividad jurídica los tratados internacionales en materia de Derechos Humanos.

Por su parte el artículo 18 de la CPEUM, donde se sustenta el sistema penitenciario de nuestro país establece lo siguiente, específicamente en el párrafo segundo:

Artículo 18. Sólo por delito que merezca pena privativa de libertad habrá lugar a prisión preventiva. El sitio de ésta será distinto del que se destinare para la extinción de las penas y estarán completamente separados.

El sistema penitenciario se organizará sobre la base del respeto a los derechos humanos, del trabajo, la capacitación para el mismo, la educación, la salud y el deporte como medios para lograr la reinserción del sentenciado a la sociedad y procurar que no vuelva a delinquir, observando los beneficios que para él prevé la ley. Las mujeres compurgarán sus penas en lugares separados de los destinados a los hombres para tal efecto.

Sin embargo este artículo debería establecer que las personas compurgaran sus penas en lugares distintos de acuerdo a su sexo e identidad de género, toda vez que no existe una dualidad de sexos exclusivamente.

\section{Ley Nacional de Ejecución Penal}

En el art 4 en los Principios Rectores del Sistema Penitenciario. Establece el principio de Igualdad, que establece:

Las personas sujetas a esta Ley deben recibir el mismo trato y oportunidades para acceder a los derechos 
reconocidos por la Constitución, Tratados Internacionales y la legislación aplicable, en los términos y bajo las condiciones que éstas señalan. No debe admitirse discriminación motivada por origen étnico o nacional, el color de piel, la cultura, el sexo, el género, la edad, las discapacidades, la condición social, económica, de salud - jurídica, la religión, la apariencia física, las características genéticas, la situación migratoria, el embarazo, la lengua, las opiniones, las preferencias sexuales, la identidad o filiación política, el estado civil, la situación familiar, las responsabilidades familiares, el idioma, los antecedentes penales o cualquier otra que atente contra la dignidad humana y con el objeto de anular - menoscabar los derechos y las libertades de las personas objeto de éstas, entre los cuales, de manera enunciativa y no limitativa, se encuentran los siguientes:

Recibir un trato digno del personal penitenciario sin diferencias fundadas en prejuicios por razón de género, origen étnico o nacional, sexo, edad, discapacidades, condición social, posición económica, condiciones de salud, religión, opiniones, preferencias sexuales 0 identidad de género, estado civil o cualquier otra que atente contra la dignidad humana

Como podemos observar el principio rector del sistema penitenciario de igualdad, establece que no existirán diferencias en prejuicios fundados en razón de género, así como en preferencias sexuales e identidad de género que atente contra la dignidad humana y no se puede condicionar el disfrute de los derechos por la orientación sexual o género, aquí ya no se establece la existencia de hombre o mujer si no se engloba la palabra persona.

De la misma ley el artículo 5. Ubicación de las personas privadas de la libertad en un Centro Penitenciario

Los Centros Penitenciarios garantizarán la separación de las personas privadas de la libertad, de conformidad con lo siguiente:

Las mujeres compurgarán sus penas en lugares separados de los destinados a los hombres;

Sin embargo es omisiva en relación a las personas LGBTTI en el lugar donde compurgaran sus penas y vuelve hacer la diferencia entre hombre y mujer, la ley debe establecer el término persona para que en la aplicación de una norma o derecho éste no sexualice el lugar donde las personas "trans" deben compurgar sus penas.

Protocolo de Actuación para quienes imparten Justicia en casos que involucren la Orientación Sexual o La Identidad De Género (2014)

No obstante que es un documento no vinculante, la autoridad no se debe de enfrascar si es vinculante o no si se tiene por objetivo auxiliar a los juzgadores en materia de Derechos Humanos en relación al respeto, protección y garantía de estos es un parámetro orientador para los jueces y operadores jurídicos en nuestro país, se debe de aplicar.

Este documento emitido por la SCJN es un documento ex profeso para aquellas personas que imparten justicia, cuando las autoridades del estado se encuentran con personas que en aras de su derecho a la libertad optaron por conducirse con otro género, en ejercicio al desarrollo de su libre personalidad, dicho protocolo se encuentra bien estructurado, con un marco conceptual, establece la forma en que el juzgador debe de actuar y la ponderación de los derechos para que exista igualdad entre grupos desiguales. Sin embargo la comunidad LBTTI ha pugnado por la existencia de un protocolo en materia de ejecución de penas del cual carece el sistema mexicano y que sería un gran avance para la existencia de un derecho "vivencial" un derecho de facto, no se trata nuevamente de la creación de nuevos derechos, si viviéramos en un Estado Democrático, estos ni siquiera se tendrían que reconocer a minorías ya que el simple hecho de ser personas todos los gozaríamos sin necesidad de luchas, sin necesidad de la existencia de protocolos, sin necesidad de que instituciones especializadas en Derechos Humanos realicen recomendaciones al Estado Mexicano, porque en un Estado real Democrático y de Derecho basándonos en el principio de igualdad, todas las personas gozaran de esos derechos no habría ni exclusión ni discriminación, requiere un cambio estructural en la cultura mexicana, una sociedad más educada, donde los valores, el respeto en reconocimiento de que no de que la estructura social no solo existen hombres y mujeres da la pauta para convivir en armonía y en una sociedad incluyente en la vida familiar, en el hogar, en la trabajo y en el ejercicio de cada uno de nuestros derechos. No se trata de crear prisiones especiales para este sector, se trata de reconocer que tienen necesidades diferentes, que son un grupo vulnerable que han sufrido y sufren violaciones a sus derechos humanos, que han sufrido agresiones sexuales, que han sido señalados por la sociedad, perseguidos por construcciones sociales creadas por sociedades que no miraban una realidad que existió existe y existirá.

Protocolo para juzgar con perspectiva de género

En 2014 a Suprema Corte de Justicia de la Nación presentó el protocolo para juzgar con perspectiva de Género" y evitar la exclusión de un grupo pequeño que históricamente ha estado en desventaja ante el propio sistema judicial, el 26 de agosto de 2014 el ministro Juan Silva Meza destaco que "este protocolo propone mecanismos para solucionar dificultades de grupos que han sido disminuidos en el goce de sus derechos por el simple hecho de ser mujeres" 
Al mismo tiempo este protocolo tiene como objetivo ayudar a las autoridades jurisdiccionales a velar por los derechos de la Convención Interamericana de Derechos Humanos conforme a su interpretación dentro de un marco constitucional mexicano.

Por su parte la SCJN emitió la siguiente jurisprudencia: "Acceso a la justicia en condiciones de igualdad. Elementos para juzgar con perspectiva de género". Del reconocimiento de los derechos humanos a la igualdad y a la no discriminación por razones de género, deriva que todo órgano jurisdiccional debe impartir justicia con base en una perspectiva de género, para lo cual, debe implementarse un método en toda controversia judicial, aun cuando las partes no lo soliciten, a fin de verificar si existe una situación de violencia o vulnerabilidad que, por cuestiones de género, impida impartir justicia de manera completa e igualitaria. Para ello, el juzgador debe tomar en cuenta lo siguiente: i) identificar primeramente si existen situaciones de poder que por cuestiones de género den cuenta de un desequilibrio entre las partes de la controversia; ii) cuestionar los hechos y valorar las pruebas desechando cualquier estereotipo o prejuicio de género, a fin de visualizar las situaciones de desventaja provocadas por condiciones de sexo o género; iii) en caso de que el material probatorio no sea suficiente para aclarar la situación de violencia, vulnerabilidad o discriminación por razones de género, ordenar las pruebas necesarias para visibilizar dichas situaciones; iv) de detectarse la situación de desventaja por cuestiones de género, cuestionar la neutralidad del derecho aplicable, así como evaluar el impacto diferenciado de la solución propuesta para buscar una resolución justa e igualitaria de acuerdo al contexto de desigualdad por condiciones de género; v) para ello debe aplicar los estándares de derechos humanos de todas las personas involucradas, especialmente de los niños y niñas; y, vi) considerar que el método exige que, en todo momento, se evite el uso del lenguaje basado en estereotipos o prejuicios, por lo que debe procurarse un lenguaje incluyente con el objeto de asegurar un acceso a la justicia sin discriminación por motivos de género.

Existe sin duda en nuestra cultura un orden binario (mujer $\mathrm{u}$ hombre) que no concuerda con la realidad en que vivimos, por tal motivo se tiene que hacer una nueva formulación de arreglos y estructuras existentes que tienden a subyugarlas (Saldivia, 2009), ya que las construcciones sociales que no permiten fácilmente encajar a otros identidad de género o preferencia sexual, de aquí no nos ocuparemos de matices biológicos ni sociales, lo cierto es que existe en la realidad que son personas y que derecho progresista, un estado Social y
Democrático de Derecho debe garantir el uso de los derechos a todas las personas sin distinción alguna.

La perspectiva de género cuestiona el paradigma de único "ser humano neutral y universal", basado en el hombre blanco, heterosexual, adulto, sin discapacidad, no indígena y en los roles que a dicho paradigma se atribuyen; por lo cual, es una estrategia que permite ver a las personas en su diversidad de contextos, necesidades y autonomía. (Uvalle, 2013)

El acceso a la justicia de una persona no solo conlleva un debido proceso legal sino un acceso integral es decir no basta que se reconozca el libre desarrollo de la persona respecto a su identidad de género u orientación sexual, su derecho a la no discriminación, si no que este acceso de la justicia aterrice igual en el lugar donde compurgara sus penas y medidas de seguridad y más allá aún donde se reintegrará a la sociedad.

El juzgador tiene la obligación que este acceso a la justicia sea apegado al principio pro persona con perspectiva de género y diversidad sexual, por mucho que se escriba, por numerosas leyes que estén en nuestro marco normativo, si nuestros operadores no conocen los derechos de todas las personas en relación a la igualdad y a la no discriminación será un trabajo infructuoso que no aterrice en la realidad.

La evolución del reconocimiento de los derechos sin distinción alguna para este sector ha dado un cambio vertiginoso y cada vez la sociedad el cambio de mentalidad para su aceptación y trato igualitario ha permeado de forma positiva en nuestra sociedad en los últimos años, no obstante, existe un vacío legal en cuanto hace a la ejecución de penas y medidas de seguridad, si bien es cierto existe un marco normativo nacional e internacional que prohíbe la discriminación y pugna por los derechos igualitarios, se encuentran precisamente en esta etapa graves violaciones a los derechos humanos, ya que mujeres y hombres "trans" son sentenciados a compurgar sus penas en prisiones para hombres y mujeres, en razón de que la discriminación es una forma de violencia (a conforme al párrafo 1 y 7 de la recomendación general 19 del comité de la eliminación de la Discriminación contra la mujer". El juez al dictar su sentencia juzgando con perspectiva de género respetando la imagen, identidad personal y sexual para la condición humana en cómo se concibe el individuo frente así y exigir al Estado las posibles violaciones, razón por la cual el juez al emitir una sentencia debe considerar la identidad personal y sexual de cómo se concibe el sujeto activo para estar en posibilidad previa audiencia de éste para enviarlo a una prisión femenil en caso de las mujeres trans.

La SCJN bajo el registro 165821 publico la siguiente tesis aislada 
Derechos a la intimidad, propia imagen, identidad personal y sexual. Constituyen derechos de defensa y garantía esencial para la condición humana.

Dentro de los derechos personalísimos se encuentran necesariamente comprendidos el derecho a la intimidad y a la propia imagen, así como a la identidad personal y sexual; entendiéndose por el primero, el derecho del individuo a no ser conocido por otros en ciertos aspectos de su vida y, por ende, el poder de decisión sobre la publicidad o información de datos relativos a su persona, familia, pensamientos o sentimientos; a la propia imagen, como aquel derecho de decidir, en forma libre, sobre la manera en que elige mostrarse frente a los demás; a la identidad personal, entendida como el derecho de todo individuo a ser uno mismo, en la propia conciencia y en la opinión de los demás, es decir, es la forma en que se ve a sí mismo y se proyecta en la sociedad, de acuerdo con sus caracteres físicos e internos y sus acciones, que lo individualizan ante la sociedad y permiten identificarlo; y que implica, por tanto, la identidad sexual, al ser la manera en que cada individuo se proyecta frente a sí y ante la sociedad desde su perspectiva sexual, no sólo en cuanto a sus preferencias sexuales sino, primordialmente, en cuanto a cómo se percibe él, con base en sus sentimientos y convicciones más profundos de pertenencia o no al sexo que legalmente le fue asignado al nacer y que, de acuerdo a ese ajuste personalísimo en el desarrollo de cada individuo, proyectará su vida en todos los ámbitos, privado y público, por lo que al ser la sexualidad un elemento esencial de la persona y de su psique, la autodeterminación sexual forma parte de ese ámbito propio y reservado de lo íntimo, la parte de la vida que se desea mantener fuera del alcance de terceros o del conocimiento público. Por consiguiente, al constituir derechos inherentes a la persona, fuera de la injerencia de los demás, se configuran como derechos de defensa y garantía esencial para la condición humana, ya que pueden reclamarse tanto en defensa de la intimidad violada o amenazada, como exigir del Estado que prevenga la existencia de eventuales intromisiones que los lesionen por lo que, si bien no son absolutos, sólo por ley podrá justificarse su intromisión, siempre que medie un interés superior.

La oficina del alto comisionado ha señalado que cuando una persona LGBTI se acerca a las instituciones judiciales o penitenciarias sufre graves abusos a sus derechos humanos así como violencia de la que son participes las propias autoridades así como tratos crueles, inhumanos y degradantes a las minorías sexuales, abusos físicos, asaltos sexuales, los transexuales consideran estar en alto riesgo de abuso sexual y físico por parte de guardias y compañeros de prisión si están en población carcelaria, principalmente de hombres. Estos grupos suelen ser muy vulnerables a Prejuicio, a la marginación y al repudio público, No sólo por las fuerzas del Estado, sino también por otros actores sociales quedando en gran medida impune la violencia ejercida a estas minorías (A/56/156, 2001)

Se pueden encontrar múltiples testimonios de personas transexuales que han sido violadas, abusadas sexualmente en reclusorios varoniles.

Vera Morales presidenta de almas cautivas en una entrevista realizada por "Sin etiquetas" un medio de comunicación digital expreso:

"No importa si su apariencia es femenina, y si su vida ya está hecha así, para las autoridades son hombres. Las chicas que llegan con una imagen femenina, son obligadas a cortarse el cabello por ejemplo. Los guardias argumentan que si están en reclusorios varoniles tienen que ser tratados como "hombres". El hecho de que un "hombre" (porque tiene pene) se vista de mujer se ve como un capricho que debe ser castigado. Para nada se respeta su identidad. Incluso aunque en algún caso tenga los papeles con su nombre femenino. Sólo hay un caso conocido de una chica trans que ya tenía la vaginoplastía y aunque sus papeles tenían un nombre masculino fue enviada a un reclusorio femenil. Es decir, la división está genitalizada. Lo que conlleva a una doble reclusión, una doble prisión. La que les quita su libertad y la que les quita su identidad" (Galeana, 2014)

Diversas organizaciones como almas cautivas han ayudado a esta comunidad a ser canalizadas a una prisión conforme a su género o a denunciar los abusos de los que han sido objeto tales como

Almas cautivas A.C.- Una asociación civil que ayudan a las personas mujeres "trans" que se encuentran compurgando una pena en un centro varonil, además de dar seguimiento para que consigan su libertad. (Solís, 2016).

Las creación de un protocolo para que las autoridades atiendan a las personas transexuales es sumamente necesario si se pretende vivir en un estado social y democrático de Derecho, no basta que el Estado mexicano firme tratados, que la SCJN realice protocolos de actuación si no operan en una realidad sería nulo todo trabajo, esfuerzos nulos, un derecho que no se vive es un derecho mudo, ciego e invisible.

\section{Conclusiones}

Un nuevo capítulo se debe de escribir de manera fáctica de manera vivaz para salvaguardar los derechos de las personas LGBTTI, en las prisiones del Estado México un estado debe de ser garante, debe de salvaguardar los 
derechos de esta comunidad, no solo en cuanto a infraestructura.

Es necesario que las autoridades del Estado mexicano conozcan los derechos de las personas LGBTTI en su detención (flagrancia/orden de aprehensión, etc.) en el proceso, y en la ejecución de penas y medidas de seguridad pero sobre todos los titulares de los mismos para poder exigirlos.

Tomar las medidas necesarias para prevenir la violencia y la discriminación en todas las etapas del proceso así como vigilar y sancionar la discriminación contra el género de una persona, diferente a su sexo.

El Estado mexicano tiene que desarrollar directrices para el tratamiento de las personas LGBTI, privadas de la libertad evitando en todo tiempo la violencia,

Garantizar la adecuada asignación al centro penitenciario que asigne el juez previa consulta y conformidad con la persona en cuestión.

El Estado mexicano tiene que emitir un protocolo de actuación en la etapa de ejecución de penas y medidas de seguridad, respetando en todo tiempo el derecho personalísimo del detenido a la discreción y al manejo de sus datos personales, así como a prevenir toda forma de discriminación motivada por su orientación sexual e identidad de género

\section{Referencias}

A/56/156, U. N. (2001). Question of torture and other cruel, inhuman or degrading treatment or punished.

Aldeberán, R. M. (29 de septiembre de 2012). Chilango. Obtenido de http://www.chilango.com/ciudad/historia-del-palacio-negro-delecumberri/

CIDH. (marzo de 2008). Principios y Buenas prácticas sobre la protección de las personas privadas de la libertad en las américas. La Comisión Interamericana de Derechos Humanos a instancia de su Relatoria sobre los Derechos de las Personas Privadas de la libertad.

Galeana, A. V. (01 de diciembre de 2014). Sin etiquetas. Obtenido de http://sinetiquetas.org/2014/12/01/mexico-lo-que-padecen-las-mujerestransexuales-en-reclusion/

Ley General para la igualdad entre mujeres y hombres ( 24 de marzo de 2016).

Naciones Unidas, O. (Nueva York, Ginebra de 2012). Nacidos Libres $e$ iguales. Ginebra: Oficina del Alto Comisionado de Naciones Unidas. Obtenido de

http://www.ohchr.org/Documents/Publications/BornFreeAndEqualLo wRes_SP.pdf

OEA. (2015). CIDH expresa preocupación por violencia y discriminación contra personas LGBT privadas de libertad. Comisión Interamericana de Derechos Humanos (CIDH), Comunicado de prensa 053/2015.

Pulgarin, M. P. (2011). Teoría y práctica de los principios de Yogyakarta en el Derecho internacional de los Derechos Humanos. Revista analisis internacional, 240.

Saldivia, L. (2009 de septimbre de 2009). Rexaminando la construcción binaria de la sexualidad. Obtenido de Yale Law School: https://law.yale.edu/system/files/documents/pdf/Student_Organizations /SELA09_Saldivia_Sp_PV.pdf
SCJN. (2013). Protocolo para juzgar con perspectiva de Género. Haciendo relidad el derecho a la igualdad. México.

SCJN. (2014). el Protocolo de Actuación para quienes imparten Justicia en casos en que se involucren la orientación sexual e identidad de género. (S. Creativas, Ed.) México, México. Recuperado el 2017 de abril de 4 , de

https://www.sitios.scjn.gob.mx/codhap/sites/default/files/archivos/pag nas/PROTOCOLO DE ACTUACION PARA QUIENES IMPART EN_JUSTICIA_EN_CASOS_QUE_INVOLUCREN_LA_ORIENTA CION_SEXUAL_O_LA_IDENTIDAD_DE_GENERO_0.pdf

Solís, D. (25 de febrero de 2016). Time out. Obtenido de https://www.timeoutmexico.mx/ciudad-de-mexico/gay-ylesbico/almas-cautivas-a-c

Uvalle, N. P. (Diciembre de 2013). Acceso a la información con perspectiva de género. El acceso a la información: una herramienta para sembrar una cultura con perspectiva de género. Obtenido de https://www.academia.edu/9065116/Acceso_a_la_informaci\%C3\%B3 n_con_perspectiva_de_g\%C3\%A9nero 